Cervical artery dissection in patients $>=60$ years Often painless, few mechanical triggers

\title{
Traenka, Christopher
}

2017-04-04

Traenka, C, Dougoud, D , Simonetti , B G, Metso , T M , Debette , S , Pezzini , A , Kloss , M , Grond-Ginsbach , C , Majersik, J J , Worrall , B B , Leys , D , Baumgartner , R , Caso , V , Bejot , Y, Compter , A, Reiner , P, Thijs , V , Southerland, A M , Bersano , A, Brandt , T , Gensicke, H , Touze , E, Martin , J J , Chabriat , H, Tatlisumak , T, Lyrer , P , Arnold , M \& Engelter , S T 2017, ' Cervical artery dissection in patients $>=60$ years Often painless, few mechanical triggers ' , Neurology , vol. 88 , no. 14 , pp. 1313-1320 . https://doi.org/10.1212/WNL.0000000000003788

http://hdl.handle.net/10138/180297

https://doi.org/10.1212/WNL.0000000000003788

unspecified

publishedVersion

Downloaded from Helda, University of Helsinki institutional repository.

This is an electronic reprint of the original article.

This reprint may differ from the original in pagination and typographic detail.

Please cite the original version. 
Christopher Traenka, MD

Daphne Dougoud, MD

Barbara Goeggel

Simonetti, MD

Tiina M. Metso, MD, PhD

Stéphanie Debette, MD,

$\mathrm{PhD}$

Alessandro Pezzini, MD

Manja Kloss, MD

Caspar Grond-Ginsbach, $\mathrm{PhD}$

Jennifer J. Majersik, MD, MS

Bradford B. Worrall, MD, MSc

Didier Leys, MD, PhD

Ralf Baumgartner, MD

Valeria Caso, MD, PhD

Yannick Béjot, MD, PhD

Annette Compter, MD,

$\mathrm{PhD}$

Peggy Reiner, MD

Vincent Thijs, MD, PhD

Andrew M. Southerland, $\mathrm{MD}, \mathrm{MSc}$

Anna Bersano, MD, PhD

Tobias Brandt, MD

Henrik Gensicke, MD

Emmanuel Touzé, MD,

$\mathrm{PhD}$

Juan J. Martin, MD

Hugues Chabriat, MD,

$\mathrm{PhD}$

Turgut Tatlisumak, MD, $\mathrm{PhD}$

Philippe Lyrer, MD

Marcel Arnold, MD*

Stefan T. Engelter, MD*

For the CADISP-Plus

Study Group

Correspondence to

Dr. Traenka:

christopher.traenka@usb.ch

\section{Supplemental data} at Neurology.org

\section{Cervical artery dissection in patients $\geq 60$}

\section{years}

\section{Often painless, few mechanical triggers}

\section{미}

\section{ABSTRACT}

Objective: In a cohort of patients diagnosed with cervical artery dissection (CeAD), to determine the proportion of patients aged $\geq 60$ years and compare the frequency of characteristics (presenting symptoms, risk factors, and outcome) in patients aged $<60$ vs $\geq 60$ years.

Methods: We combined data from 3 large cohorts of consecutive patients diagnosed with CeAD (i.e., Cervical Artery Dissection and Ischemic Stroke Patients-Plus consortium). We dichotomized cases into 2 groups, age $\geq 60$ and $<60$ years, and compared clinical characteristics, risk factors, vascular features, and 3-month outcome between the groups. First, we performed a combined analysis of pooled individual patient data. Secondary analyses were done within each cohort and across cohorts. Crude and adjusted odds ratios (OR [95\% confidence interval]) were calculated.

Results: Among 2,391 patients diagnosed with CeAD, we identified 177 patients (7.4\%) aged $\geq 60$ years. In this age group, cervical pain (OR adjusted 0.47 [0.33-0.66]), headache $\left(\mathrm{OR}_{\text {adjusted }}\right.$ $0.58[0.42-0.79])$, mechanical trigger events $\left(\mathrm{OR}_{\text {adjusted }} 0.53[0.36-0.77]\right)$, and migraine $\left(\mathrm{OR}_{\text {adjusted }} 0.58\right.$ [0.39-0.85]) were less frequent than in younger patients. In turn, hypercholesterolemia ( $\mathrm{OR}_{\text {adjusted }} 1.52$ [1.1-2.10]) and hypertension ( $\mathrm{OR}_{\text {adjusted }} 3.08$ [2.25-4.22]) were more frequent in older patients. Key differences between age groups were confirmed in secondary analyses. In multivariable, adjusted analyses, favorable outcome (i.e., modified Rankin Scale score $0-2)$ was less frequent in the older age group ( $\left.\mathrm{OR}_{\text {adjusted }} 0.45[0.25,0.83]\right)$.

Conclusion: In our study population of patients diagnosed with CeAD, 1 in 14 was aged $\geq 60$ years. In these patients, pain and mechanical triggers might be missing, rendering the diagnosis more challenging and increasing the risk of missed CeAD diagnosis in older patients. Neurology ${ }^{\circledR}$ 2017;88:1313-1320

\section{GLOSSARY}

CADISP-Plus $=$ Cervical Artery Dissection and Ischemic Stroke Patients-Plus; CeAD $=$ cervical artery dissection; $\mathbf{C l}=$ confidence interval; IPD = individual patient data; $\mathbf{m R S}=$ modified Rankin Scale; NIHSS = NIH Stroke Scale; OR = odds ratio.

Cervical artery dissection (CeAD) is uncommon in the general population, but it is a major cause of stroke in the young. ${ }^{1,2}$ The majority of patients with CeAD are aged 40-50 years at CeAD occurrence. ${ }^{1,3}$ In patients aged 60 years and above, atherosclerosis, small vessel disease, or cardioembolism dominate as mechanisms of ischemic stroke. ${ }^{4}$ Although there are few reports

\footnotetext{
*These authors contributed equally to this work.
}

From the Department of Neurology and Stroke Center (C.T., H.G., P.L., S.T.E.), University Hospital Basel and University of Basel; Department of Neurology (D.D., B.G.S., M.A.), University Hospital Berne; Ospedale San Giovanni (B.G.S.), Bellinzona, Switzerland; Department of Neurology (T.M.M., T.T.), Helsinki University Central Hospital, Finland; Department of Neurology (S.D.), Bordeaux University Hospital; Inserm U1219 (S.D.), Bordeaux; Bordeaux University (S.D.), France; Department of Neurology (S.D.), Boston University School of Medicine, MA; Department of Clinical and Experimental Sciences (A.P.), Neurology Clinic, University of Brescia, Italy; Department of Neurology (M.K., C.G.-G.), Heidelberg University Hospital, Germany; Department of Neurology (J.J.M.), University of Utah, Salt Lake City; Departments of Neurology and Public Health Sciences (B.B.W., A.M.S.), University of Virginia Health System, Charlottesville; Univ Lille 2 (D.L.), INSERM U 1171, CHU Lille, France; Neuro Center (R.B.), Clinic Hirslanden, Zurich, Switzerland; Stroke Unit and Division of Internal and Cardiovascular Medicine (V.C.), University of Perugia, Italy; Centre Hospitalier Universitaire Le Bocage (Y.B.), Dijon, France; Department of Neurology and Neurosurgery (A.C.), Brain Centre Rudolf Magnus, University Medical Centre Utrecht, the Netherlands; Department of Neurology (P.R., H.C.), Lariboisière Hospital, Paris 7 University, DHU Neurovasc Sorbonne Paris Cité, France; Florey Institute of Neuroscience and Mental Health (V.T.); Department of Neurology (V.T.), Austin Health, Heidelberg, Australia; Cerebrovascular Unit (A.B.), IRCCS Foundation C. Besta Neurological Institute, Milan, Italy; Clinics for Neurologic Rehabilitation (T.B.), Kliniken Schmieder, Heidelberg, Germany; Normandie Univ (E.T.), UNICAEN, Inserm U919, Department of Neurology, CHU Caen; Department of Neurology (E.T.), CH Sainte-Anne, University Paris Descartes, France; Department of Neurology (J.J.M.), Sanatorio Allende, Cordoba, Argentina; Department of Neurology (T.T.), Sahlgrenska University Hospital and Institute for Neuroscience and Physiology, Sahlgrenska Academy at University of Gothenburg, Sweden; and Neurorehabilitation Unit (S.T.E.), University of Basel and University Center for Medicine of Aging and Rehabilitation, Felix Platter Hospital, Basel, Switzerland. Coinvestigators are listed at Neurology.org.

Go to Neurology.org for full disclosures. Funding information and disclosures deemed relevant by the authors, if any, are provided at the end of the article. 
about $\mathrm{CeAD}$ in patients in their 60s and $70 s, 5,6$ the frequency of characteristics (presenting symptoms, risk factors, and outcome) in this age group of patients with $\mathrm{CeAD}$ remains unknown.

The profile of patients with CeAD seems to be different in younger and older age groups. ${ }^{7}$ For CeAD patients $\geq 60$ years, an age group where $\mathrm{CeAD}$ is considered less frequent, it remains unknown if clinical characteristics, vascular findings, and 3-month outcome differ compared to younger patients. Such data are clinically important: first, CeAD is commonly thought of as a disease in the young ${ }^{1}$ and therefore clinicians might not consider CeAD in older patients. Second, knowledge of the characteristics of CeAD for patients $\geq 60$ years is important to inform appropriate diagnostic and treatment decisions in the older age group.

With these considerations in mind, we aimed to (1) determine the proportion of patients with CeAD aged $\geq 60$ years and (2) identify the characteristics of patients with CeAD aged $\geq 60$ years compared to those aged $<60$ years. We analyzed the extended dataset of the multicenter Cervical Artery Dissection and Ischemic Stroke Patients-Plus (CADISPPlus) consortium. ${ }^{8,9}$

METHODS Study population and data collection. The updated dataset of the multicenter CADISP-Plus consortium comprises 2,426 patients with CeAD including patients from the CADISP clinical study (CADISP-1 cohort: $n=983$ patients and CADISP-2 cohort [US centers]: $\mathrm{n}=312$ patients) and the Paris-Lariboisière/Zurich/Bern CeAD registry ( $\mathrm{n}=$ 1,131 patients). The detailed structure and methods of each of these clinical cohorts have been described in detail. ${ }^{9-11}$ All sites from these cohorts applied the same widely accepted diagnostic $\mathrm{CeAD}$ criteria and definitions of key variables allowing pooled analyses. ${ }^{8}$ There was, however, no standardized surveillance across cohorts and age groups (i.e., standardized assessments were not uniformly performed on all stroke patients to assess for CeAD). In brief, diagnostic criteria of CeAD (for internal carotid or vertebral artery) were defined as follows: presence of a mural hematoma, aneurysmal dilation, long tapering stenosis, intimal flap, double lumen, or occlusion situated $>2 \mathrm{~cm}$ above the carotid bifurcation revealing an aneurysmal dilation or a long tapering stenosis after recanalization. ${ }^{8}$ An overview of the cohorts is given in the eMethods at Neurology.org.

Patient characteristics and variable definitions. The following demographic, clinical, and imaging data were obtained for individual patients from each cohort as done in previous research $^{8,12,13}$ : age, sex, vascular risk factors according to predefined criteria (i.e., presence or absence of hypertension, hypercholesterolemia, and diabetes),${ }^{14}$ site of dissection (i.e., internal carotid artery, vertebral artery, both internal carotid and vertebral artery), ${ }^{15}$ pathologic features of the dissected artery (i.e., presence or absence of a vessel occlusion),$^{15}$ presenting symptoms including ischemic stroke, TIA, and local signs and symptoms (i.e., Horner syndrome, headache, and cervical pain) ${ }^{13}$ presence or absence of putative $\mathrm{CeAD}$ risk factors (i.e., migraine ${ }^{16}$ and prior mechanical trigger events ${ }^{12}$ ), and stroke severity as assessed by the NIH Stroke Scale score (NIHSS). Functional outcome was assessed during outpatient visits or telephone calls using the modified Rankin Scale (mRS) at 3 months. Excellent functional outcome was defined as an $\mathrm{mRS}$ score of $0-1$, favorable outcome as an mRS score of $0-2$. Patients with a history of polytrauma within the prior 4 weeks were excluded from the current analysis. Detailed definitions of each of these variables were published previously. ${ }^{8,9,11}$

Statistical analyses. Patient baseline demographic and clinical data were compared between patients with CeAD aged $\geq 60$ years and those $<60$ years. First, we compared variables between groups (i.e., $\geq 60$ vs $<60$ ) across all patients from every cohort in the form of a combined analysis based on pooled individual patient data (IPD). For categorical variables, differences between groups were assessed using the $\chi^{2}$ test, or the Fisher exact test if suitable. Differences in continuous variables were calculated using the Mann-Whitney test. Multivariable logistic regression analysis was performed with adjustment for sex and site of dissection (i.e., internal carotid vs vertebral artery dissection). ${ }^{7}$ For analysis of 3month outcome, we adjusted for stroke severity (NIHSS) and occlusion of the dissected artery as the most important outcome predictors in CeAD. ${ }^{17}$ Based on the results of the univariate analyses, we also adjusted for diagnoses of hypertension and hypercholesterolemia. A $p$ value $<0.05$ was considered statistically significant.

For the secondary analyses, we performed (1) univariate and adjusted multivariable comparisons between age groups within each separate cohort and (2) meta-analyses across all 3 clinical cohorts by using a fixed-effects Mantel-Haenszel model with calculation of odds ratios (ORs) and corresponding 95\% confidence intervals (CIs). Heterogeneity across study cohorts was assessed using the $F^{2}$ index. As post hoc analyses we compared patients aged $\leq 45$ years to those aged $\geq 65$ years in unadjusted, univariate comparisons on the IPD dataset.

Standard protocol approvals, registrations, and patient consents. Local authorities and ethics committees approved protocols for the included cohorts from all participating centers. Data collection and analyses were conducted according to national rules of approval and informed consent of the included patients.

RESULTS Patient demographics. A total of 2,391 patients with CeAD out of 2,426 patients were eligible for analysis. Among these, we identified 177 (7.4\%) patients aged $\geq 60$ years. The overall median age of all consecutive patients with CeAD included in this study was 45 years (interquartile range 38-52). Patient demographics and clinical characteristics are presented in table 1 (across all patients) and tables e- 1 through e-3 (separately for each study cohort). In patients aged $\geq 60$ years, male patients were predominant $(67.8 \%$ of those $\geq 60$ years old vs $55.8 \%<60$ years old; $p_{\text {unadjusted }}=0.002$; table 1 ).

Patient clinical characteristics and putative risk factors. Combined analysis of pooled IPD and meta-analysis across study cohorts. Patients aged $\geq 60$ years presented less 


\begin{tabular}{|c|c|c|c|c|c|c|c|}
\hline \multirow[t]{3}{*}{ Table 1} & \multirow[b]{3}{*}{ All patients $(\mathrm{n}=2,391)$} & \multirow[b]{3}{*}{$<60$ y $(n=2,214)$} & \multirow[b]{3}{*}{$\geq 60$ y $(n=177)$} & \multirow{2}{*}{\multicolumn{2}{|c|}{$\geq 60$ y vs $<60$ y, unadjusted analysis }} & \multirow{2}{*}{\multicolumn{2}{|c|}{260 y vs $<60$ y, adjusted analysis }} \\
\hline & & & & & & & \\
\hline & & & & $p$ Value & OR $(95 \% \mathrm{Cl})$ & $p$ Value & OR $(95 \% \mathrm{Cl})$ \\
\hline Sex, female (\%) & 1,036/2,391 (43.3) & $979 / 2,214(44.2)$ & 57/177 (32.2) & $0.002^{\mathrm{a}}$ & $0.6(0.43-0.83)$ & NA & \\
\hline Age, y, median (IQR) & 45 (38-52) & $44(37-50)$ & $63(61-67)$ & NA & & NA & \\
\hline Mechanical trigger event, $\mathrm{n}(\%)^{\mathrm{b}}$ & $744 / 2,370(31.4)$ & 708/2,193 (з2.3) & $36 / 177$ (20.3) & $0.001^{a}$ & $0.54(0.37-0.78)$ & $0.001^{\mathrm{a}}$ & $0.53(0.36-0.77)$ \\
\hline Migraine, $\mathrm{n}(\%)^{\mathrm{b}}$ & 739/2,358 (31.3) & 704/2,183 (з2.2) & $35 / 175(20)$ & $0.001^{a}$ & $0.53(0.36-0.77)$ & $0.005^{\mathrm{a}}$ & $0.58(0.39-0.85)$ \\
\hline Hypercholesterolemia, $n(\%)^{c}$ & 727/2,174 (33.4) & $655 / 2,009(32.6)$ & $72 / 165(43.6)$ & $0.004^{a}$ & $1.6(1.16-2.21)$ & $0.011^{\mathrm{a}}$ & $1.52(1.1-2.10)$ \\
\hline Hypertension, $n(\%)^{c}$ & $621 / 2,341(26.5)$ & $531 / 2,165(24.5)$ & $90 / 176(51.1)$ & $<0.001^{\mathrm{a}}$ & $3.22(2.36-4.4)$ & $<0.00^{\mathrm{a}}$ & $3.08(2.25-4.22)$ \\
\hline Diabetes, $\mathrm{n}(\%)^{c}$ & $66 / 2,346(2.8)$ & $51 / 2,170(2.4)$ & 15/176 (8.5) & $<0.001^{\mathrm{a}}$ & $3.87(2.13-7.04)$ & $<0.001^{\mathrm{a}}$ & $3.80(2.09-6.93)$ \\
\hline Ischemic stroke or TIA, $n(\%)^{b}$ & 1,682/2,391 (70.3) & $1,565 / 2,214(70.7)$ & $117 / 177(66.1)$ & 0.199 & $0.81(0.59-1.12)$ & 0.218 & $0.81(0.59-1.13)$ \\
\hline Horner syndrome, n (\%) & 715/2,362 (30.3) & $660 / 2,186$ (30.2) & $55 / 176$ (31.3) & 0.769 & $1.05(0.75-1.46)$ & 0.832 & $0.96(0.68-1.36)$ \\
\hline Cervical pain, n (\%) & $1,048 / 2,359(44.4)$ & $999 / 2,183(45.8)$ & $49 / 176(27.8)$ & $<0.001^{\mathrm{a}}$ & $0.46(0.33-0.64)$ & $<0.001^{\mathrm{a}}$ & $0.47(0.33-0.66)$ \\
\hline Headache, $\mathrm{n}(\%)^{\mathrm{b}}$ & $1,579 / 2,360(66.9)$ & $1,484 / 2,185(67.9)$ & $95 / 175$ (54.3) & $<0.001^{\mathrm{a}}$ & $0.56(0.41-0.77)$ & $0.001^{\mathrm{a}}$ & $0.58(0.42-0.79)$ \\
\hline Occlusion, $\mathrm{n}(\%)^{\mathrm{b}}$ & 805/2,381 (33.8) & $752 / 2,214$ (34) & $53 / 167(31.7)$ & 0.557 & $0.90(0.65-1.27)$ & 0.454 & $0.88(0.63-1.23)$ \\
\hline NIHSS at admission, mean $( \pm S D)^{d}$ & $6.3(6.9)$ & $6.4(7)$ & $5.4(6)$ & 0.168 & $0.98(0.95-1.01)$ & 0.136 & $0.97(0.94-1.01)$ \\
\hline Excellent outcome (mRS 0-1), n (\%) & $1,490 / 2,025(73.6)$ & $1,377 / 1,868(73.7)$ & $113 / 157$ (72) & 0.635 & $0.92(0.64-1.32)$ & 0.155 & $0.71(0.45-1.14)$ \\
\hline Favorable outcome (mRS 0-2), $n(\%)^{e}$ & $1,769 / 2,025(87.4)$ & $1,638 / 1,868(87.7)$ & 131/157 (83.4) & 0.124 & $0.71(0.45-1.10)$ & $0.01^{a}$ & $0.45(0.25-0.83)$ \\
\hline Internal carotid artery dissection, $n(\%)^{c}$ & $1,603 / 2,391(67)$ & $1,479 / 2,214(66.8)$ & 124/177 (70.1) & 0.375 & $1.16(0.83-1.62)$ & 0.502 & $1.12(0.80-1.57)$ \\
\hline Vertebral artery dissection, $\mathrm{n}(\%)^{\mathrm{c}}$ & 889/2,391 (37.2) & $829 / 2,214(37.4)$ & 60/177 (33.9) & 0.348 & $0.86(0.62-1.18)$ & 0.520 & $0.9(0.95-1.24)$ \\
\hline
\end{tabular}

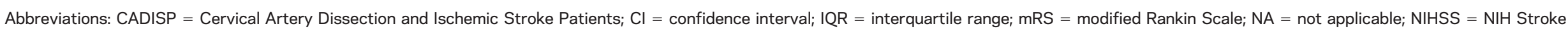
Scale; OR = odds ratio; PZB = Paris-Lariboisière/Zurich/Bern CeAD registry.

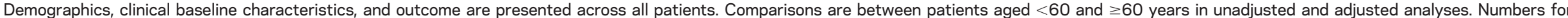

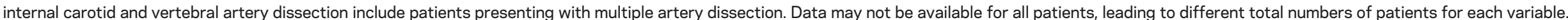
a Significant.

${ }^{\mathrm{b}}$ Adjusted for sex and internal carotid artery as site of dissection.

${ }^{\mathrm{c}}$ Adjusted for sex.

${ }^{\mathrm{d}}$ Adjusted for sex and internal carotid artery as site of dissection (in patients with any cerebral ischemia [ischemic stroke or TIA]).

${ }^{\text {e}}$ Adjusted for sex, internal carotid artery as site of dissection, occlusion of the dissected artery, NIHSS at baseline, and diagnoses of hypertension and hypercholesterolemia. 
Figure 1 Forest plots of the meta-analyses across all 3 clinical cohorts (Cervical Artery Dissection and Ischemic Stroke Patients [CADISP]-1, CADISP-2, and Paris-Lariboisière/Zurich/Bern CeAD registry [PZB])

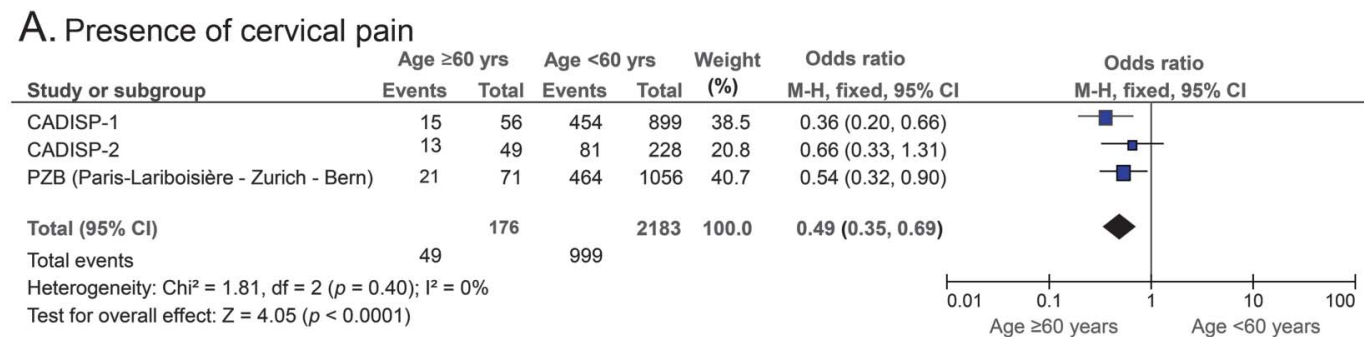

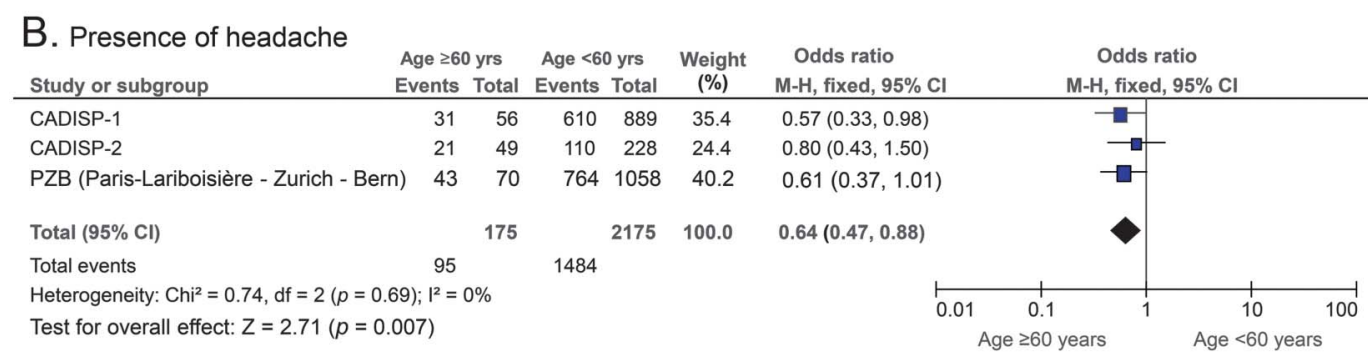

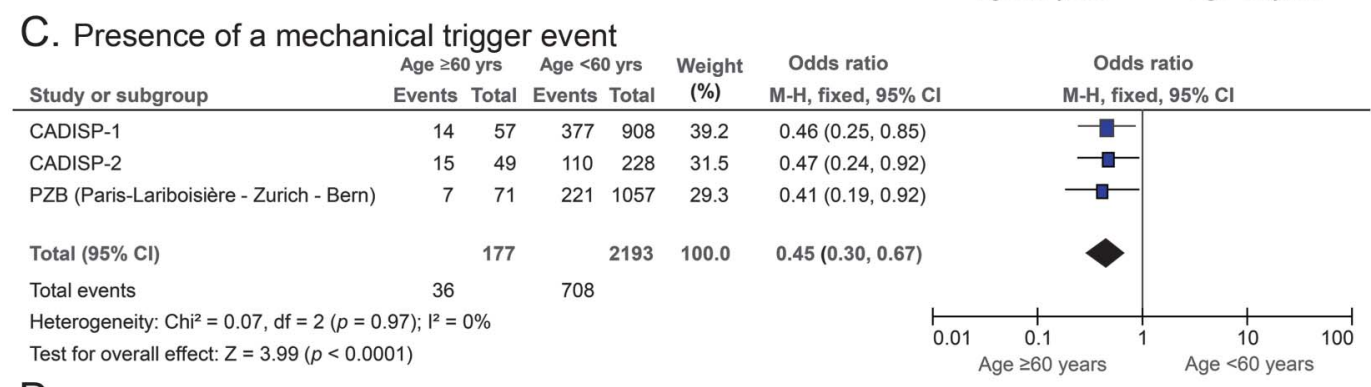

\section{Presence of hypertension}

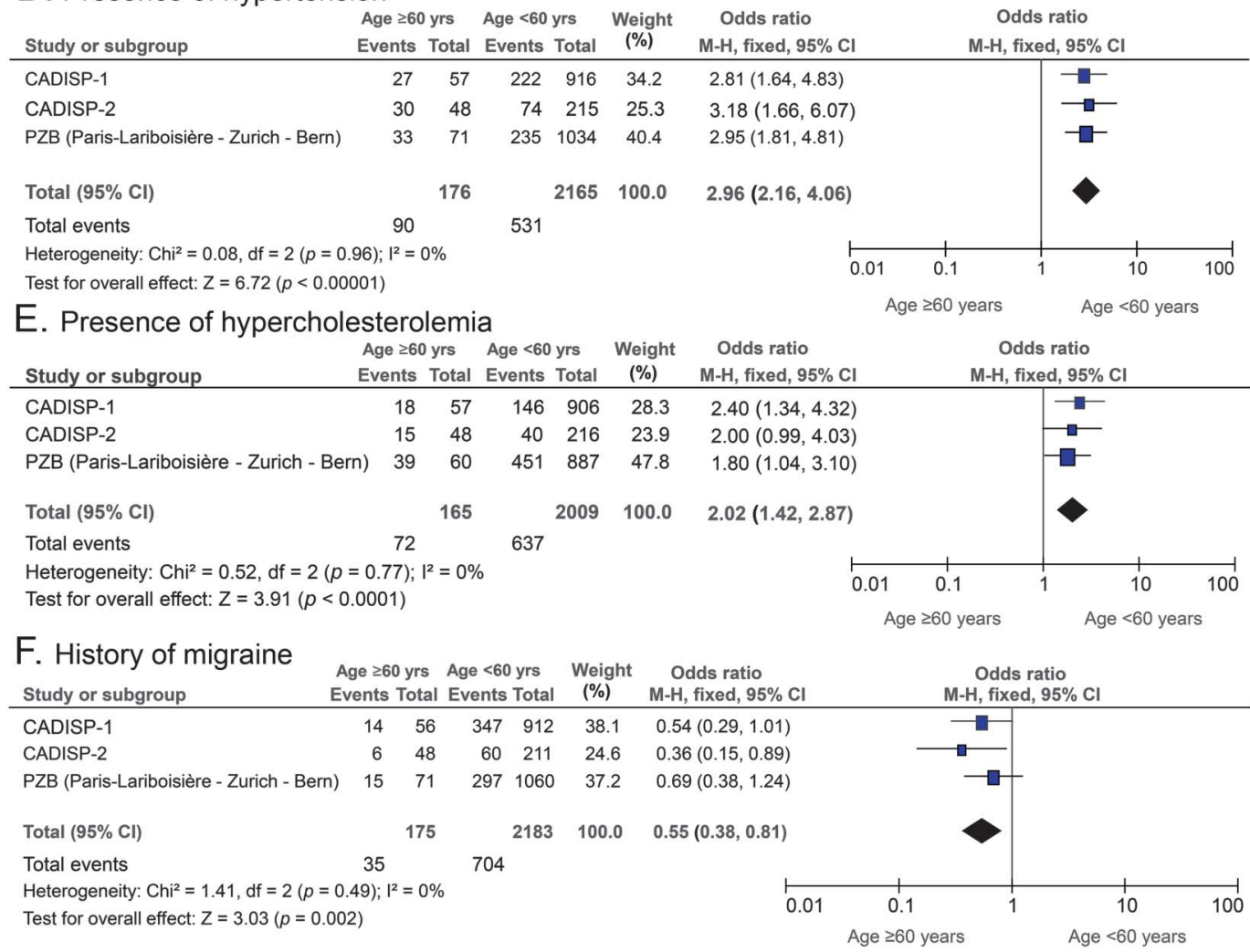

(A-F) Frequency of patient characteristics were compared between patients aged $\geq 60$ years and $<60$ years. A fixedeffects Mantel-Haenszel (M-H) model was used, with calculation of unadjusted odds ratios (ORs) and corresponding $95 \%$ confidence intervals $(\mathrm{Cls})$. Heterogeneity across study cohorts was assessed using the $I^{2}$ index. Results of those analyses showing significant differences between the age groups are presented. 
frequently with cervical pain or headache (cervical pain, IPD: $\mathrm{OR}_{\text {adjusted }} 0.47$ [0.33-0.66]; headache, IPD: $\mathrm{OR}_{\text {adjusted }} 0.58$ [0.42-0.79]) (table 1 and figure $1)$. In contrast, an equal proportion of patients in each age group presented with Horner syndrome $(31.3 \%$ [ $\geq 60$ years] vs $30.2 \%$ [ $<60$ years]). This held true for Horner syndrome in the absence of pain, other local signs of CeAD (i.e., tinnitus, cranial nerve palsy), or mechanical trigger events $(n=8$ [20\%, age $\geq 60$ years] vs $\mathrm{n}=54$ [26.7\%, age $<60$ years], $p_{\text {unadjusted }}=$ $0.884)$. Likewise, cerebral ischemic events (i.e., ischemic stroke or TIA) at CeAD onset occurred at similar rates in both young and older patients with CeAD (table 1 and figure e-1).

Mechanical trigger events prior to CeAD onset were significantly less common in patients aged $\geq 60$ years (IPD: $\mathrm{OR}_{\text {adjusted }} 0.53$ [0.36-0.77]; table $1)$. Migraine was also less frequent in older patients with CeAD (IPD: OR adjusted 0.58 [0.39-0.85]; table 1). In contrast, hypercholesterolemia (IPD: $\mathrm{OR}_{\text {adjusted }}$ 1.52 [1.1-2.10]), hypertension (IPD: OR ${ }_{\text {adjusted }} 3.08$ [2.25-4.22]), and diabetes (IPD: $\mathrm{OR}_{\text {adjusted }} 3.8$ [2.09-6.93]) were more common in patients with CeAD aged $\geq 60$ years.

For the distribution of the site of dissection (internal carotid or vertebral artery), as well as the occlusion of the dissected artery, there was no significant difference between the 2 age groups in primary (IPD) or secondary analyses (table 1, tables e-1 through e-3, and figure e-1). Post hoc analyses of the first antithrombotic treatment after CeAD diagnosis revealed the following results: overall, 2,191 patients $(91.6 \%)$ received any antithrombotic therapy after diagnosis of CeAD $(n=164$ [92.7\% of patients aged $\geq 60]$ and $n=2,027$ [91.6\% of patients aged <60]). Anticoagulants were used significantly less often in patients aged $\geq 60$ years (patients receiving anticoagulants: $\mathrm{n}=82[50 \%$, age $\geq 60]$ vs $\mathrm{n}=1,295$ [63.9\%, age $<60]$, $p_{\text {unadjusted }}<0.001$ ).

Unadjusted analysis of favorable functional outcome (i.e., mRS 0-2) at 3 months did not show a difference between the age groups (IPD: $\mathrm{OR}_{\mathrm{unad}}$ justed 0.71 [0.45-1.10]). However, after adjustment (for sex, site of dissection, occlusion of the dissected artery, NIHSS, hypertension, and hypercholesterolemia), the analysis revealed a lower likelihood of a favorable outcome in patients with CeAD aged $\geq 60$ years (IPD: OR adjusted $0.45 \quad[0.25,0.83]$ ) (table 1).

Key findings on differences between age groups showed similar results in primary analyses (of combined data and within each cohort) as well as the secondary analyses (in meta-analyses across cohorts). To look for extremes of effect, we further performed unadjusted post hoc analyses comparing characteristics of patients aged $\leq 45$ years to those aged $\geq 65$ years (i.e., removing those aged 46-64 years old). We focused on variables that showed statistically significant differences between age groups in our primary analyses. This post hoc analyses mainly confirmed our primary results, with all associations being in the same direction of effect, and only the frequency of mechanical trigger events losing significance ( $p_{\text {unadjusted }}=$ 0.073; table e-4).

Detailed information on the distribution of characteristics and risk factors are given in table 1 and tables e- 1 through e- 4 , as well as figure 1 and figure e-1.

DISCUSSION In this large compilation of individual data of patients diagnosed with CeAD, our analyses on proportion and characteristics of patients with CeAD aged $\geq 60$ years revealed the following key findings. First, $7 \%$ of the patients with CeAD in our study population were aged $\geq 60$ years. Second, in the studied population, compared to those aged $<60$ years, patients with CeAD aged $\geq 60$ years were more often male, but were less likely to have painful $\mathrm{CeAD}$, a preceding mechanical trigger event, or a history of migraine. Third, in this population, age $\geq 60$ years was independently associated with less favorable outcome after CeAD.

Until now, the frequency of patients aged $\geq 60$ years among patients with CeAD has not been systematically studied. In a small CeAD cohort, over $30 \%$ (11 of 34) of patients with CeAD were reported to be aged $>60$ years. ${ }^{6}$ Although limited by a small sample size, this number indicated that $\mathrm{CeAD}$ in elderly patients might occur more frequently than suspected in a disease characterized as primarily affecting younger age groups. ${ }^{1-3}$ Our analysis of a large, multicenter dataset found that 1 out of 14 patients with CeAD was 60 years or older. The $95 \%$ CI (6.4-8.5) in our analysis indicated that this rate could even be as high as every 11 th CeAD patient. In addition, there was a clear male preponderance in this age group, in line with previous findings. ${ }^{7}$

Cervical pain and headache are common local symptoms in patients with CeAD. ${ }^{11,15}$ However, our analysis revealed that cervical pain is not a hallmark of CeAD in patients $\geq 60$ years. We can only speculate on the reasons for this observation. Pain in CeAD most likely arises directly from the irritation of nerves surrounding the dissected vessel. ${ }^{18,19}$ An agerelated decrease in nociceptors might be a hypothetical explanation for this observation. In addition, there is evidence of the association of increasing age with increasing arterial (carotid) stiffness. ${ }^{20}$ Increasing arterial stiffness in older patients leading to a decreased distensibility of the cervical arteries may play a role in a reduction of periarterial nerve irritation in CeAD and thereby a reduction of painful local symptoms. 
Older patients with CeAD less frequently report a history of migraine. Migraine - in particular without aura-has been associated with CeAD in prior studies. Compared to age- and sex-matched ischemic stroke patients without $\mathrm{CeAD}$, a history of migraine was significantly more common among patients with CeAD. ${ }^{16,21}$ In the general population, migraine is most common among middle-aged adults, ${ }^{22}$ and it is more common among female patients. ${ }^{22,23}$ Thus, the effect seen in our analysis may reflect the age and sex distribution of migraine in the general population. In turn, hypertension and hypercholesterolemia were significantly more common among older patients with CeAD compared to younger ones. In general, compared to age- and sex-matched healthy referents, patients with $\mathrm{CeAD}$ are more frequently hypertensive but show a lower prevalence of hypercholesterolemia. ${ }^{14}$

In patients with CeAD aged $\geq 60$ years, mechanical trigger events were reported only in one fifth of patients, which is significantly less frequent than in younger patients (one third). Mechanical trigger events seem to play an important role in CeAD pathophysiology, as they are significantly more prevalent in $\mathrm{CeAD}$ as compared to ischemic stroke patients without CeAD and healthy subjects. ${ }^{12}$ The underlying reason for a lower frequency of such trigger events in older patients remains elusive. It might point at a less physically active lifestyle of older patients, thereby reducing the risk of CeAD in older individuals. However, age-dependent differences in pathophysiology of CeAD cannot be ruled out. For instance, the dissecting mechanism of CeAD in older patients may arise intrinsically in the artery rather than from external forces. ${ }^{24}$ Further, mechanical trigger events, in particular minor traumas, may play a subordinate role in older patients with $\mathrm{CeAD}$ as the arteries may be less susceptible to mechanical stress given the increased arterial stiffness in older patients.

Our observation that patients with CeAD aged $\geq 60$ often lack pain and mechanical trigger events — characteristics considered suggestive for CeADindicates the possibility that $\mathrm{CeAD}$ might be underdiagnosed in this age group. Compared to younger patients, investigations to diagnose CeAD might be ordered less often in this age group, as CeAD is considered a disease of young to middle-aged adults and typical clinical CeAD signs and symptoms seem infrequent in those aged $\geq 60$ years. Signs of CeAD in routine neurovascular imaging might be subtle. The likelihood of clinicians missing or overlooking such subtle signs, or of performing incomplete vascular imaging, might be increased if clinicians do not consider CeAD as potential cause of symptoms.

In our cohort, patients with $\mathrm{CeAD}$ aged $\geq 60$ had less favorable outcome than younger patients, which is in line with findings in ischemic stroke patients without CeAD. ${ }^{7}$

A major strength of our study is the large sample size, which reduces the risks of chance findings and allows adjustment for potential confounders. Further, the design of our analyses proves that our findings are solid: the major results of the IPD were confirmed by analyses within each separate cohort as well as by meta-analyses across all 3 cohorts. Moreover, baseline characteristics and outcomes have been collected according to standardized criteria irrespective of and therefore unbiased by the present research question.

Still, we are aware of the following limitations: (1) the data used in this analysis are based on large hospital-based cohorts of CeAD patients, which are non-randomized and were not monitored; (2) the size of the age groups differs considerably; (3) our dataset did not comprise information on the presence of genetic factors, precluding analyses on the role of such factors in age subgroups or the interaction with acquired risk factors; and (4) there were no predefined surveillance procedures in the study cohorts, which may lead to an ascertainment bias. As a consequence, the age distribution found in our cohorts may not represent the true distribution in CeAD. In addition, differential ascertainment based on different exposures and risk factors in the different age groups might impair the reliability of our findings on the frequency of risk factors and clinical characteristics within each age group. We acknowledge that our data do not allow us to define strict criteria on which patients should undergo a specific evaluation for CeAD, in particular since we did not include a comparison group of patients without CeAD. For the latter reasons, we were unable to provide data on the frequency of CeAD in all stroke patients aged $\geq 60$.

Our analyses of large hospital-based cohorts of patients diagnosed with CeAD in departments of neurology in tertiary hospitals suggest that in this setting 1 in 14 patients with CeAD is aged $\geq 60$ years. Compared to younger age groups, CeAD in persons aged $\geq 60$ years is more often painless and lacking identifiable mechanical trigger events, which renders the diagnosis more challenging. As older patients with $\mathrm{CeAD}$ may have less favorable outcomes, it is important to be aware of the risk and consider CeAD among other more frequent stroke subtypes in these age groups.

\section{AUTHOR CONTRIBUTIONS}

C.T. designed/conceptualized the study, analyzed/interpreted the data, drafted the manuscript, and collected data. M.A. supervised the study, analyzed/interpreted the data, revised the manuscript, and collected data. S.T.E. initiated, designed, conceptualized, and supervised the study, analyzed/interpreted the data, revised the manuscript, and collected data. All authors collected data, performed critical review of the manuscript, and edited the manuscript for content. 


\section{STUDY FUNDING}

The 3 cohorts of the CADISP-Plus consortium received funding from the Contrat de Projet Etat-Region 2007, Centre National de Genotypage, Institut Pasteur de Lille, INSERM U744, Emil Aaltonen Foundation, Paavo Ilmari Ahvenainen Foundation, Helsinki University Central Hospital Research Fund, Academy of Finland, Helsinki University Medical Foundation, Päivikki and Sakari Sohlberg Foundation, Aarne Koskelo Foundation, Maire Taponen Foundation, Aarne and Aili Turunen Foundation, Lilly Foundation, Alfred Kordelin Foundation, Finnish Medical Foundation, Orion Farmos Research Foundation, Maud Kuistila Foundation, the Finnish Brain Foundation, Projet Hospitalier de Recherche Clinique Régional, Fondation de France, Génopôle de Lille, Adrinord, EA2691, Institut Pasteur de Lille, Inserm U744, Basel Stroke-Funds, Käthe-Zingg-Schwichtenberg-Fonds of the Swiss Academy of Medical Sciences, the Swiss National Science Foundation (33CM30124119, 33CM30-140340/1), Swiss Heart Foundation, University of Basel, University Hospital Basel Science Funds (Wissenschaftsfonds), Chair of Excellence grant from the French National Research Agency (Agence Nationale de la Recherche), the Leducq Foundation, and the Clinical Investigatorship from FWO Flanders.

\section{DISCLOSURE}

C. Traenka, D. Dougoud, and B. Simonetti report no disclosures relevant to the manuscript. T. Metso has received funding from the Finnish Medical Foundation, Helsinki University Central Hospital Research Fund, Helsinki University Medical Foundation, Orion Farmos Research Foundation, Päivikki and Sakari Sohlberg Foundation, Maire Taponen Foundation, the Lilly Foundation, Paavo Ilmari Ahvenainen Foundation, Aarne and Aili Turunen Foundation, Aarne Koskelo Foundation, the Maud Kuistila Memorial Foundation, Emil Aaltonen Foundation, Finnish Brain Foundation, and Alfred Kordelin Foundation. S. Debette, A. Pezzini, M. Kloss, and C. Grond-Ginsbach report no disclosures relevant to the manuscript. J. Majersik is a member of the editorial board of Neurology ${ }^{\circledR}$ (no compensation). B. Worrall is a deputy editor of Neurology and received modest salary support from this grant. D. Leys has participated during the last 5 years with advisory boards, symposia, or trials sponsored by Sanofi-Aventis, BMS, AstraZeneca, Boehringer Ingelheim, Servier, Ebewe, CoLucid Pharm, BrainsGate, PhotoThera, Lundbeck, GSK, Bayer, Pfizer, and Allergan (honorarium paid to Adrinord or research account of the hospital), and served as associate editor of the Journal of Neurology, Neurosurgery and Psychiatry, 2004-2010 (personal financial compensation). R. Baumgartner reports no disclosures relevant to the manuscript. V. Caso has served as a speaker for Boehringer Ingelheim, Sanofi, and Pfizer. Y. Béjot has served as a member of a scientific committee for Boehringer-Ingelheim France and received honoraria for participation in advisory boards or as a symposium speaker for AstraZeneca France, Daiichi-Sankyo, Pfizer, Covidien, and MSD France. A. Compter and P. Reiner report no disclosures relevant to the manuscript. V. Thijs has received funding for travel or speaker honoraria from Bayer, Boehringer Ingelheim, Pfizer Inc., and Medtronic; has served on scientific advisory boards for Shire, Bayer, Pfizer, and Boehringer Ingelheim, and on the editorial board of Stroke; is an associate editor of Acta Neurologica Belgica; and has received honoraria for being on the steering committee of the AX200 trial (SYGNIS). A. Southerland is the deputy podcast editor for Neurology and has received a grant from the American Heart Association for a research study of gene expression in cervical artery dissection (AHA 3CRP141400001) and received modest salary support from this grant. A. Bersano has received funding for travel and congress participation from Shire, Boehringer Ingelheim, and Sanofi-Aventis. T. Brandt and $\mathrm{H}$. Gensicke report no disclosures relevant to the manuscript. E. Touzé has served on scientific advisory boards for Bayer Schering Pharma, Pfizer, BMS, and Shire; has received speaker honoraria from Boehringer Ingelheim, Bayer Schering Pharma, Pfizer, BMS, and Shire; has received funding for travel from AstraZeneca and BMS; serves as assistant editor for Stroke; and has received research support from the French Ministry of Health. J. Martin has served on the editorial board of The European Neurological Journal since May 2009 (no compensation). H. Chabriat has served on scientific advisory boards for Lundbeck and Janssen and is a member of the editorial board (cerebrovascular disease). $T$. Tatlisumak has research contracts with Boehringer-Ingelheim, BrainsGate,
Pfizer, and Bayer, and advisory board memberships for BoehringerIngelheim, BrainsGate, Medfield Diagnostics, Pfizer, and Bayer. P. Lyrer has served on scientific advisory boards for Bayer Schering Pharma and Boehringer Ingelheim; has received funding for travel or speaker honoraria from Bayer Schering Pharma, Boehringer Ingelheim, and Shire plc; serves as coeditor for Neurologie und Psychiatrie and on the editorial board of Swiss Archives of Neurology and Psychiatry; and has received research support from AstraZeneca, Boehringer Ingelheim, Sanofi-Aventis, PhotoThera, the Swiss National Science Foundation, and the Swiss Heart Foundation. M. Arnold serves on scientific advisory boards for Bayer Schering, Boehringer Ingelheim, and Pfizer/BMS; received speaker honoraria from Bayer Schering, Boehringer Ingelheim, and Covidien; and received research grants from the Swiss National Science Foundation, the Swiss Heart Foundation, SHIRE Human Genetics, and BRAHMS GmbH. S. Engelter has received funding for travel or speaker honoraria from Bayer and Boehringer Ingelheim; has served on scientific advisory boards for Bayer, Boehringer Ingelheim, BMS/Pfizer, and Covidien, and on the editorial board of Stroke; and has received an educational grant from Pfizer and research support from the Science Funds (Wissenschaftsfonds) of the University Hospital Basel, the University Basel, the Swiss Heart Foundation, and the Swiss National Science Foundation. Go to Neurology.org for full disclosures.

Received June 17, 2016. Accepted in final form January 12, 2017.

\section{REFERENCES}

1. Debette $\mathrm{S}$, Leys D. Cervical-artery dissections: predisposing factors, diagnosis, and outcome. Lancet Neurol 2009; 8:668-678.

2. Goeggel Simonetti B, Mono ML, Huynh-Do U, et al. Risk factors, aetiology and outcome of ischaemic stroke in young adults: the Swiss Young Stroke Study (SYSS). J Neurol 2015;262:2025-2032.

3. Lee VH, Brown RD Jr, Mandrekar JN, Mokri B. Incidence and outcome of cervical artery dissection: a populationbased study. Neurology 2006;67:1809-1812.

4. Nacu A, Fromm A, Sand KM, Waje-Andreassen U, Thomassen L, Naess H. Age dependency of ischaemic stroke subtypes and vascular risk factors in western Norway: the Bergen Norwegian Stroke Cooperation Study. Acta Neurol Scand 2016;133:202-207.

5. Pelkonen O, Tikkakoski T, Leinonen S, Pyhtinen J, Lepojarvi M, Sotaniemi K. Extracranial internal carotid and vertebral artery dissections: angiographic spectrum, course and prognosis. Neuroradiology 2003;45:71-77.

6. Ahl B, Bokemeyer M, Ennen JC, Kohlmetz C, Becker H, Weissenborn K. Dissection of the brain supplying arteries over the life span. J Neurol Neurosurg Psychiatry 2004;75: 1194-1196.

7. Metso TM, Debette S, Grond-Ginsbach C, et al. Agedependent differences in cervical artery dissection. J Neurol 2012;259:2202-2210.

8. Debette S, Goeggel Simonetti B, Schilling S, et al. Familial occurrence and heritable connective tissue disorders in cervical artery dissection. Neurology 2014;83:2023-2031.

9. Debette S, Kamatani Y, Metso TM, et al. Common variation in PHACTR1 is associated with susceptibility to cervical artery dissection. Nat Genet 2015;47:78-83.

10. Debette S, Metso TM, Pezzini A, et al. CADISP-genetics: an international project searching for genetic risk factors of cervical artery dissections. Int J Stroke 2009;4:224-230.

11. von Babo M, De Marchis GM, Sarikaya H, et al. Differences and similarities between spontaneous dissections of the internal carotid artery and the vertebral artery. Stroke 2013;44:1537-1542. 
12. Engelter ST, Grond-Ginsbach C, Metso TM, et al. Cervical artery dissection: trauma and other potential mechanical trigger events. Neurology 2013;80:19501957.

13. Lyrer PA, Brandt T, Metso TM, et al. Clinical import of Horner syndrome in internal carotid and vertebral artery dissection. Neurology 2014;82:1653-1659.

14. Debette S, Metso T, Pezzini A, et al. Association of vascular risk factors with cervical artery dissection and ischemic stroke in young adults. Circulation 2011;123: 1537-1544.

15. Debette S, Grond-Ginsbach C, Bodenant M, et al. Differential features of carotid and vertebral artery dissections: the CADISP study. Neurology 2011;77:1174-1181.

16. Metso TM, Tatlisumak T, Debette $S$, et al. Migraine in cervical artery dissection and ischemic stroke patients. Neurology 2012;78:1221-1228.

17. Engelter ST, Dallongeville J, Kloss M, et al. Thrombolysis in cervical artery dissection: data from the Cervical Artery Dissection and Ischaemic Stroke Patients (CADISP) database. Eur J Neurol 2012;19:1199-1206.
18. Sheikh HU. Headache in intracranial and cervical artery dissections. Curr Pain Headache Rep 2016;20:8.

19. Caplan LR. Dissections of brain-supplying arteries. Nat Clin Pract Neurol 2008;4:34-42.

20. Urbina EM, Srinivasan SR, Kieltyka RL, et al. Correlates of carotid artery stiffness in young adults: the Bogalusa Heart Study. Atherosclerosis 2004;176:157-164.

21. Pezzini A, Granella F, Grassi M, et al. History of migraine and the risk of spontaneous cervical artery dissection. Cephalalgia 2005;25:575-580.

22. Lipton RB, Bigal ME, Diamond M, et al. Migraine prevalence, disease burden, and the need for preventive therapy. Neurology 2007;68:343-349.

23. Bigal ME, Liberman JN, Lipton RB. Age-dependent prevalence and clinical features of migraine. Neurology 2006; 67:246-251.

24. Callaghan FM, Luechinger R, Kurtcuoglu V, Sarikaya H, Poulikakos D, Baumgartner RW. Wall stress of the cervical carotid artery in patients with carotid dissection: a casecontrol study. Am J Physiol Heart Circ Physiol 2011;300: H1451-H1458.

\section{Save These Dates for AAN CME Opportunities!}

Mark these dates on your calendar for exciting continuing education conferences by the American Academy of Neurology. Learn more at $A A N$.com/conferences.

\section{AAN Annual Meeting}

- April 22-28, 2017, Boston, MA, at the Boston Convention Center

\section{Sports Concussion Conference}

- July 14-16, 2017, Jacksonville, FL, at the Hyatt Regency Jacksonville Riverfront

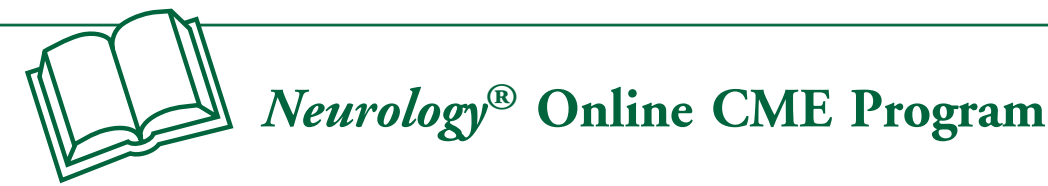

Earn CME while reading Neurology. This program is available only to online Neurology subscribers. Simply read the articles marked CME, go to Neurology.org, and click on CME. This will provide all of the information necessary to get started. The American Academy of Neurology (AAN) is accredited by the Accreditation Council for Continuing Medical Education (ACCME) to sponsor continuing medical education for physicians. Neurology is planned and produced in accordance with the ACCME Essentials. For more information, contact AAN Member Services at 800-879-1960. 


\section{Neurology}

Cervical artery dissection in patients $\geq 60$ years: Often painless, few mechanical triggers Christopher Traenka, Daphne Dougoud, Barbara Goeggel Simonetti, et al. Neurology 2017;88;1313-1320 Published Online before print March 3, 2017

DOI 10.1212/WNL.0000000000003788

This information is current as of March 3, 2017

\begin{tabular}{|c|c|}
\hline $\begin{array}{l}\text { Updated Information \& } \\
\text { Services }\end{array}$ & $\begin{array}{l}\text { including high resolution figures, can be found at: } \\
\text { http://www.neurology.org/content/88/14/1313.full.html }\end{array}$ \\
\hline Supplementary Material & $\begin{array}{l}\text { Supplementary material can be found at: } \\
\text { http://www.neurology.org/content/supp1/2017/03/03/WNL.0000000000 } \\
\text { 003788.DC1 } \\
\text { http://www.neurology.org/content/supp1/2017/03/03/WNL.0000000000 } \\
\text { 003788.DC2 }\end{array}$ \\
\hline References & $\begin{array}{l}\text { This article cites } 24 \text { articles, } 12 \text { of which you can access for free at: } \\
\text { http://www.neurology.org/content/88/14/1313.full.html\#\#ref-list-1 }\end{array}$ \\
\hline Subspecialty Collections & $\begin{array}{l}\text { This article, along with others on similar topics, appears in the } \\
\text { following collection(s): } \\
\text { All Cerebrovascular disease/Stroke } \\
\text { http://www.neurology.org//cgi/collection/all_cerebrovascular_disease_ } \\
\text { stroke } \\
\text { Carotid artery dissection } \\
\text { http://www.neurology.org//cgi/collection/carotid_artery_dissection } \\
\text { Stroke in young adults } \\
\text { http://www.neurology.org//cgi/collection/stroke_in_young_adults }\end{array}$ \\
\hline Permissions \& Licensing & $\begin{array}{l}\text { Information about reproducing this article in parts (figures,tables) or in } \\
\text { its entirety can be found online at: } \\
\text { http://www.neurology.org/misc/about.xhtml\#permissions }\end{array}$ \\
\hline Reprints & $\begin{array}{l}\text { Information about ordering reprints can be found online: } \\
\text { http://www.neurology.org/misc/addir.xhtml\#reprintsus }\end{array}$ \\
\hline
\end{tabular}

Neurology ${ }^{\circledR}$ is the official journal of the American Academy of Neurology. Published continuously since 1951, it is now a weekly with 48 issues per year. Copyright @ 2017 American Academy of Neurology. All rights reserved. Print ISSN: 0028-3878. Online ISSN: 1526-632X.

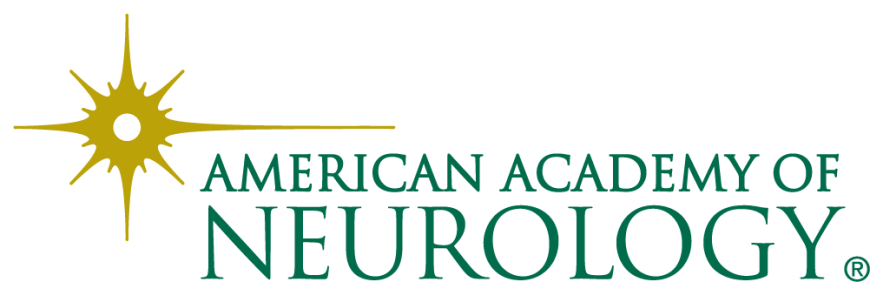

